\title{
AN ONLINE LEARNING MODEL TO FACILITATE LEARNERS’ RIGHTS TO EDUCATION
}

\author{
Lin Lin \\ Assistant Professor of Learning Technologies \\ University of North Texas
}

\begin{abstract}
This paper connects an online learning model to the rights to education that the online educational environments can provide. The model emerges from a study of ninety-two online learners and is composed of three kinds of inquiries, namely, independent inquiry, collaborative inquiry, and formative inquiry towards expert knowledge. Online learners naturally pursue and undertake these inquiries when they are equipped with communication channels and technologies. This model provides a thinking tool for integrating new media and technologies in an online learning environment in order to help students achieve their full rights to education.
\end{abstract}

\section{KEY WORDS}

Learners' Rights; Online Learning Environments; Self-directed Learning, Independent Inquiry, Collaborative Inquiry, Formative Inquiry towards Expert Knowledge

\section{INTRODUCTION}

"Everyone has the right to education. ... Education shall be directed to the full development of the human personality and to the strengthening of respect for human rights and fundamental freedoms."

Article 26 (1\&2), Universal Declaration of Human Rights, United Nations, 12/10/1948 [1]

Online learning can and should play an active role in ensuring the right to education, especially the right for all individuals to develop to their fullest potential. To take on this role, we need to see the "right" to education as plural instead of singular. The "right" and "rights" to education include not only the right to access information, the right to use and share information, but more importantly, the right to question authority and that which is projected as truth, the right to create and co-create knowledge and information, the right to modify and update one's own and others' knowledge, and the right to own and to be recognized for the creation and co-creation of the knowledge and information. According to Freire, "knowledge emerges only through invention and reinvention, through the restless, impatient, continuing, hopeful inquiry men (and women - added by the author) pursue in the world, with the world, and with each other" [2, p. 58]. Only when the learners have the opportunity and are able to invent and reinvent "in the world, with the world, and with each other" [2, p. 58] will they be on the road to achieve their full rights to education.

It has been more than 59 years since the United Nations General Assembly approved and published the 
Universal Declaration of Human Rights in General Assembly resolution 217 A (III) (http://www.un.org/Overview/rights.html). Only three short years after the end of World War II, the collective consciousness and global will manifested itself to produce that proclamation which had, as one of its primary goals, the prevention of similar global conflagrations through enlightenment and respect for the human state. Education was then and is now seen as the path to realizing its hopeful fulfillment. In those 59 years that followed, the world would witness such changes that few could have imagined, including such astounding advancements as the mapping of the human genome, the dramatic spread of the personal computer and birth of the Internet, and the manufacture and development of the cell phone and Global Positioning Satellite (GPS) systems. Information Technology superseded manufacturing technology in most countries and our world society moved from a modern to a postmodern milieu.

In Article 26 of these declared rights, it was made clear that these member nations of the UN agreed that everyone had the right to education regardless of race, religion, sex, language, or political persuasion, that education should be free at least in the elementary stages, and that higher education in its technical and professional forms would be accessible based on merit. Further it was declared that education should be directed towards the full development of the human personality and that it would engender human rights, respect for others and protect fundamental freedoms. Concurrently it would promote understanding, tolerance and friendship among all nations, racial or religious groups, and further the activities of the United Nations for the maintenance of peace.

Article 26 of this resolution though, is not meant to be interpreted alone and for the sole purpose of education, since it must be considered in the larger context of all 30 of the articles of this declaration. To view it as a standalone proclamation would not do it justice in the larger sense for which it was intended, namely the movement towards world peace and improvement of the human state. Clearly as stated, the long range goal of the United Nation was then and is now the promotion of human social progress, understanding, tolerance, and world peace.

The purpose of this paper is to share an online learning model which links and enables these rights. The model emerges from a recent research study and is composed of three dynamic areas which derive from the learners' activities and interactivities through online learning. These areas are: 1) independent inquiry 2) collaborative inquiry, and 3) formative inquiry towards expert knowledge. We can think of these inquiries as being directly linked to an individual's personal rights to independent thinking, the right to collaborate, and the right to personal transcendence, transformation, or formative expertise. In the larger context of the Universal Declaration of Human Rights we can think of these as tied to other articles of the declaration as well. Article 18 seeks to guarantee the right to freedom of thought which can be seen as the right to independent inquiry, Article 20 guarantees the right to freedom of peaceful assembly, while Article 27 speaks of the right to participate in the cultural life of a community, both directly linked to what I would call the right to collaborate, and finally what I refer to as the right to transcendency, transformation, or formative expertise can be seen as being guaranteed by Article 26 itself. In the following, I will describe the literature that underscores this online model, the emergence of the model, the connection of this model to new media and technology, and the implications of this model for the rights to education. 


\section{LITERATURE}

"He who would teach us a truth should situate us so that we discover it ourselves."

- José Ortega y Gasset

\section{A. Study, Self-directed Learning and Independent Inquiry}

In his essay "Toward a place for study in a world of instruction," McClintock [3] convincingly argues for the significance of study, the inward driven study, in one's education and life. Using Montaigne as an example, McClintock highlights the fact that education is "a continuous heightening of consciousness, an unceasing sharpening of judgment," and that "teaching and learning might impart knowledge," whereas "study led to understanding, whereby things known were made one's own and became a part of one's judgment” [3, p. 162]. Study, as further illustrated by McClintock, is neither a single path nor the final goal; it is the motivating power by which we "form and impose our character upon our role in life" (p. 163). Through study, we reach out to the resources of nature, faith, and reason to select those that best suit our situations and to develop capacities to achieve our goals. "In this art of study, each component of culture has a part to play, and every component of art, literature, science, and thought can be seen as educational in a rigorous sense” [3, p. 163].

Inward driven study referenced by McClintock is more commonly known as self-directed learning, which is advocated by scholars such as Candy [4], Brookfield [5], Knowles [6], Merriam [7, 8], and Tough [9]. Self-directed learning has been a cornerstone of adult education for over three decades. In 1971, Tough began to explore how adults engage in independent learning projects throughout their lifetime [9]. In 1975, Malcolm Knowles provided adult educators and learners with a guide for learning independently and autonomously [6]. Since that time, many scholars and practitioners have worked to elaborate on models of self-directed learning and to implement self-directed learning programs. Candy [4] outlined four facets of self-directed learning: self management, learner control, autodidaxy, and autonomy. Studies by these and many other scholars provide sufficient evidence that adults are interested in and capable of being self-directed learners.

Self-directed learning and lifelong learning have become increasingly important in our new world, with fast-changing technologies and ever increasing amounts of new information [10]. All adults are faced with the pressure to continuously update their knowledge and skills in order to keep up with their work and life situations. Hence, there emerged an increasing need for flexible and convenient learning opportunities, afforded by new media and technologies. Distance education, especially online learning, is one of the prominent areas that have greatly benefited from the advancement of new media and technologies, and as a result, has helped extend educational opportunities and rights to learners of various backgrounds. Distance learning has greatly extended access that would otherwise be unavailable [11, 12, $13,14,15,16,17]$, offered flexibility that meets the learners' needs [11, 18, 19, 20, 21, 22], afforded multiple and alternative ways of learning that satisfy individual differences [11, 23, 21], encouraged independent and self-directed learning [24, 25, 26, 27, 28], facilitated reflective and higher-order thinking [29, 30, 31, 32, 33], and taken advantage of new media and technologies that are, or become recursive parts of learner's personal and professional lives [34, 35, 36, 37, 38]. 


\section{B. Collaborative Inquiry, Dialogue, and Co-Construction of Knowledge}

The concept of study or self-directed learning seems to be simple and natural, but in reality, it has been one of the most difficult practices to implement in our education or lives. Advocating self-direction does not mean that learners do not need support or direction. As well advocated by Brookfield [5, 10, 39], adult learning is not necessarily always joyful or motivated by heart-felt needs; on the contrary, all adult learners experience feelings of "impostorship" (posing as something one is not), "cultural suicide" (being excluded from one's culture of origin), "lost innocence” (losing the innocent sense of absolute truth), "incremental fluctuation" (anxiety over the gap between the old thinking and the new knowledge or capability), and a sense of disconnectedness from a community at various stages of their learning process. To help adult learners deal with issues of self-doubt, dialogue and collaborative inquiry become the social glue that holds individual learning experiences together [2, 40]. Often, real learning occurs in the process of dialoguing and interacting with learners, teachers, and experts, not simply in the receiving of content. Vygotskian theorists share the assumption that the structure of consciousness comes about through situated, goal-directed, tool-mediated engagement in social practices [41].

Gadamer [42] and Buber and Freidman [43] point out that the meaning of dialogue is found in neither one nor the other of the partners, nor in both added together, but in their interchange; therefore, it transcends the subjective opinions of the partners individually, such that even the person leading the conversation is always surprised and seeks to advance understanding for all partners [42]. Buber and Freidman [43] refer to this as the element of "surprise," since one can never be certain what the other will offer at each new turn. Buber believes that real educators teach most successfully when they are not consciously trying to teach, but when they act spontaneously and authentically out of their own life experiences. Accepting and confirming each other as a person builds trust between the educator and the learner, helps the learner gain confidence in the meaning in human existence, and kindles the learner's curiosity, interest, and desire for inquiry about the unknown. The dialectic as the art of conducting a conversation is the art of seeing things in the unity of an aspect, that is, it is the art of the formation of concepts as the working out of the common meaning [26].

Both Bohm [40] and Freire [2] emphasize treating all participants as equals as pre-requisite for a true dialogue. Freire believes that without all participants being treated as equals, dialogue cannot continue. If a participant feels superior or does not trust the other participants, he or she will not concentrate on the topic but on the underlying issues of trust and agenda-making. Bohm [40] and Freire [2] believe that all participants must be involved in the process of setting the pedagogical steps to co-create the new knowledge that is relevant to the participants' and learners' needs. Without the direct connection to the learners' felt needs, the intended dialogue breaks down and results only in silence [2]. Therefore, each engagement with the learners will be different and co-created with them; the purpose will be specific to the learners' needs; and dialogue will act as the flow of meaning. In a true dialogue, all participants come to a new understanding of their knowledge, beliefs, values, feelings, and judgments. By the same token, Buber [44] elevates dialogue to the significant level of human existence. According to Buber, human beings' access to being is through "the between"-the dialogue between man and the existent other against him. Buber believes that no one can know another simply as he knows objects (I-it), and that Ithou, the relationship between human beings, involves a "real encounter and genuine mutuality" [43, p. 50]. The equal relationship is a precondition to ensure that one person's rights are not impeded by another person.

When collaborating online, the focus on the teacher's monological transfer of information is being toned down. Now it is the social relations, the differences and harmony between the different voices, that constitute knowledge. In light of Vygotsky's [45] theory of “zone of proximal development," the dialogue through an online medium such as a discussion forum can be considered as a meeting spot where the 
participants meet the challenges presented as they themselves see them from their individual zones of proximal development. Vygotsky defined the zone of proximal development as "the distance between the actual development level as determined by independent problem solving and the level of potential developed as determined through problem solving under adult guidance or in collaboration with more capable peers" [45, p. 86]. The dialogue becomes a meeting between a diversity of zones of development, where the tensions between the different levels of knowledge and understanding function as the principal factor in the struggle for a collective development of knowledge. The purpose is then to allow all the participants to reach their levels of potential development, and in relation to the levels of competence required by the curriculum.

With respect to online learning, Garrison, Anderson, and Archer [29, 30] developed a model that highlights the importance of the development of social presence in the process. Their model of critical thinking and practical inquiry describes learning as occurring through the interaction of three overlapping core components: cognitive presence, teaching presence, and social presence [29, 30]. Cognitive presence, social presence, and teaching presence can only take place in a collaborative learning environment. What characterizes a collaborative environment is open, mindful, and free discussion, where argumentation in is considered as an important learning activity [46, 47, 48]. In accordance with this view, it is important that the participants always be encouraged to alternate between the individual learning perspective and the collective one [47]. Salomon points out that a basic condition for real collaboration is the genuine interdependence of the participants [47]. This means an interdependence that is not caused by participants being forced to collaborate, but by the fact that the participants have complementary competences from which the group as a whole will necessarily benefit. Everyone in the group becomes dependent on the others. The individual learner's awareness in the learning activity, in particular in the collaborative part of it, will be an important precondition for learning.

\section{Expert Knowledge and Formative Inquiry towards Expert Knowledge}

Expert knowledge or expertise "is based on a deep knowledge of the problems that continually come up on a specific job and is accumulated over years of experience tackling these problems" [49, p. 120]. An expert recognizes and reacts by chunking, that is, grouping relevant patterns together and ignoring irrelevant patterns so as to concentrate on the critical ones [49].

Bransford, Pellegrino, and Donovan [50] list several key principles of experts' knowledge, emphasizing that the six principles of expertise need to be considered simultaneously as parts of an overall system:

1. Experts notice features and meaningful patterns of information that are not noticed by novices.

2. Experts have acquired a great deal of content knowledge that is organized in ways that reflect a deep understanding of their subject matter.

3. Experts' knowledge cannot be reduced to sets of isolated facts or propositions but, instead, reflects contexts of applicability: that is, the knowledge is "conditionalized" on a set of circumstances.

4. Experts are able to flexibly retrieve important aspects of their knowledge with little attentional effort.

5. Though experts know their disciplines thoroughly, this does not guarantee that they are able to teach others.

6. Experts have varying levels of flexibility in their approach to new situations.

According to Bransford et al., the ability to monitor one's approach to problem-solving-to be metacognitive - is an important aspect of expert competence, and "students need to develop the ability to teach themselves” [51, p. 38]. This is in line with McClintock’s advocating for inward study. McClintock 
explains the concept in reference to Plato: teachers "could not fruitfully instruct those who would not teach themselves, who would only respond passively to the most convenient appearance; the most teachers could do was to convert such inert souls to active study" [3, p. 12]. According to McClintock, the truth "is in the experiences that each of us has ... The value of words and theories is not that they communicate truth, but that ... they may help us grasp and comprehend the truths of our experience” [3, p. 56].

An educator can facilitate the process of helping learners be teachers of their own learning. This role is especially useful when a learner or a group of learners start the journey. The facilitator can help identify assumptions, model respectful behavior, and record all the thoughts, even if this merely means creating a "parking lot" of recorded ideas for later discussion or clarification. In a dialogical environment, a facilitator can make sure the entire group is honored and involved in the dialogue. A good facilitator helps reflect and re-phrase the participants' thoughts and helps set the appropriate dwell time to pace the conversation so as not to leave a point before it has been appropriately investigated, as well as not to dwell on the unimportant or trivial.

In his Pedagogy of the Oppressed, Paulo Freire [2] provides a good example of a facilitator. In the process of co-creating curricula with the learners, Freire engaged a group of assistants who acted as process translators and interpreters for the dialogic process. Freire used a sociologist, anthropologist, psychologist, and linguist to help set the stage in a historical sense. However, in Freire's process, none of these facilitators assumed the role of a director. While developing the themes and codifications required for his pedagogy, these facilitators acted as co-creators with the learners to create the themes and select the encoded objects of discussion about which the learning will transpire. Freire believes that in order to enroll and motivate the learners-dialoguers, everyone must be involved in the process of setting the pedagogical steps.

Obviously, the facilitator can be one of the enablers or experts in the learning environments. Yet, he or she does not need to be, cannot be, and is not recommended to be the expert in any given learning environments because, as mentioned earlier, it is more beneficial for the learners to see themselves succeeding in the development of their own expertise and knowledge. Additionally, it is important for the learners to see the value of their own contributions, their peers' contributions, and the creation of their shared meaning in an interdependent learning environment or community. Learners can become better self-directed learners when they not only have the opportunity to undertake their inquiries within their own time frame, but also have a community they can go to for help, and to which they can contribute. Lave and Wenger [51] first used the term Community of Practice (CoP) to discuss situated learning as part of an attempt to rethink learning within working groups. Since then, "CoP" has been used to denote the process of social learning that occurs when people who have a common interest to collaborate over an extended period of time to share ideas, find solutions, and build innovative constructs. Such a "CoP" can emerge now at a distance as a result of new media and technologies. Social networking software and programs have made distance collaboration not only a reality but a necessity for today's learners to achieve their rights to education.

This research focuses on the learners' experiences in online learning community, where they strive for expert knowledge through independent and collaborative inquiries.

\section{Research Questions}

In order to understand the learners' experience of learning online, the following issues were examined: 1) What is the nature of interactions in online dialogue? 2) What are learners' responses and perceptions of online dialogue? 


\section{EMERGENCE OF THE ONLINE LEARNING MODEL}

\section{A. Research Method}

The phenomenological approach was used to answer these questions and to understand the meaning and quality of the learners' experiences, primarily from the perspective of those participants being studied. Van Manen [52] holds a view that phenomenology serves as the rationale behind the efforts to understand individuals by entering into their field of perception in order to see life as these individuals see it. In order to ascertain the experiences of an online dialogue, it would be desirable to learn directly from the dialoguers about their perceptions of their online interactions.

Phenomenological researchers agree that three research processes compose the phenomenological method: investigation of the phenomena, identification of general themes/essences of the phenomena, and comprehension of essential relationships among themes [52, 53]. In phenomenology, the researcher first details the individual statements of informants about experiences with the phenomenon before moving to meanings and clusters of meanings. This inductive approach to developing the qualitative narrative shows that the process is one of an emerging design. The purpose of phenomenological inquiry is to discover the essential meaning or existential experience of what it is like to live through a certain experience, although the "meaning or essence of a phenomenon is never simple or one-dimensional. Meaning is multidimensional and multi-layered" [52, p. 78]. According to van Manen, "in order to come to grips with the structure of meaning it is helpful to think of the phenomenon described in the text as approachable in terms of meaning units, structure of meaning, or themes. Reflecting on lived experience then becomes reflectively analyzing the structural or thematic aspects of that experience" [52, p. 78]. This statement is especially interesting and intriguing as regards this study, because part of "the lived experience" in the study was itself in the text format (the threaded written discussions) and was written by the student himself or herself when he or she was experiencing the phenomenon or the medium. It was the goal of the study to investigate the unique experiences of the participant students with online dialogue.

An important part of this research was devoted to discovering what encouraged meaningful dialogue and co-construction of new knowledge in online activities and interactions. To find answers to such questions, it is best to allow the participants to speak for themselves. As the researcher discovered from the study, the participants with their individual differences and multiple perspectives are often the only ones who can put their finger on the true constraints and benefits of learning through various forms of the online medium. Their insights are usually wrapped up in their personal value systems, life goals, and past experiences, which may not be readily apparent to the researcher. In addition, more often than not, the participants' own words capture the most critical and seminal issues of their experience as they learned through online dialogue.

\section{B. Data Collection}

Ninety-two (out of 221) students from seven online courses participated in the study. The seven courses were offered in three different departments: Cognition and Human Development, Organization and Leadership, and Mathematics, Science, and Technology. Among the 92 participants, 17 were male and 73 were female (two participants did not indicate their gender and age). Half of the participants (46 students) were between the age range of 20-29; 28 were between 30 and 39; 12 between 40 and 49; and 4 between 50 and 59 years of age. Most participants had a full-time or part-time job in addition to being a graduate student. About half the participants indicated that they were educators, professors, teachers, or researchers at colleges, schools, or institutes. The others indicated that they were administrators, directors, managers, editors, specialists, generalists, or producers at organizations. Three-fourths of the participants were native English speakers. Other languages spoken included Chinese (10 people), Korean (6 people), Japanese (3 people), Spanish (3 people), and Russian, Hebrew, Italian, German, Hindi, and Greek. About 
two-thirds of the participants had taken more than one online courses before the study, while the other one-third of the participants were taking an online course for the first time during the study.

The participants gave permission for the researcher to access their online discussions. They also responded to two online surveys. One survey was a password protected online learning style inventory called P.E.T. (Personal Empowerment through Type), which was used to determine the individual learners' preferred and auxiliary psychological type preferences [54, 55, 56]. Another instrument was a survey designed to find out the learners' perceived experiences, satisfactions, or frustrations with online dialogue. The survey included 21 questions, of which 14 were open-ended questions seeking the participants' perceptions of their experiences, while seven others were questions seeking demographic information such as occupation and numbers of online courses taken.

The responses to the open-ended survey questions were analyzed and synthesized by three researchers before the discussion postings were examined. The detailed analysis and synthesis of the study from the angle of psychological type preferences were published in the Teachers College Record [23]. The responses to the two survey instruments provided insights into the continued inquiries of the research, especially as relevant to the question regarding the individual learners' affective responses and perceptions toward the asynchronous and written nature of the dialogue. Therefore, this paper focuses on the other question of the research, which is: what are the culture of use and the nature of interactions in online dialogue? The threaded discussions were analyzed for this purpose.

The process of coding the online texts is a process of simultaneous pattern development, analysis, and synthesis. Open coding is used to examine the online experience-the phenomenon exhibited through the "authentic" texts and context of the online communications. NVivo, a qualitative data software package that combines data management, analysis, and synthesis, was used for open coding.

Three kinds of inquiries emerged from the individuals' online activities and interactivities: the independent inquiry, the collaborative inquiry, and the formative inquiry towards expertise. The three inquiries are briefly discussed in the findings below while details can be found in How Adults Learn through Online Asynchronous Written Dialogue [57]. Postings from the participants were selected to illustrate the findings and arguments.

\section{Limitation}

The first and most obvious limitation of this research is that the study relied heavily on the written textsthe written responses from the survey questionnaire and the discussion postings from the participants. Therefore, it missed the verbal and non-verbal cues normally observed and relied on in a phenomenological study. The study is heavily influenced by the researcher's own voice and many conversations that the researcher has had with the online course professors and students; yet, the researcher did not collect interviews specifically for this study. Therefore, some specific nuances might have been missed in the study.

Another limitation of the study is that not all students, 92 out of 221, granted their permission to the study. This required the researcher to analyze the discussion postings through individual postings rather than analyze the threaded discussions as a coherent piece. As a result, the ability to see the nature of the collaborative effort was limited. It is also possible that those who did not participate in the study were somehow different from those who did. In addition, students enrolled in online courses self-selected mostly. They might be predisposed already to non-traditional education methods. Furthermore, the 
sample from one university may or may not be representative of the online graduate course students at other institutions.

\section{Findings}

The study discovered that learners were naturally involved in three kinds of inquiries, which the author identified as independent inquiry, collaborative inquiry, and formative inquiry towards expertise or expert knowledge. The following figure (figure 1) shows the relationship of the three kinds of inquiries:

Figure 1. The Relationship of the Three Kinds of Inquiries

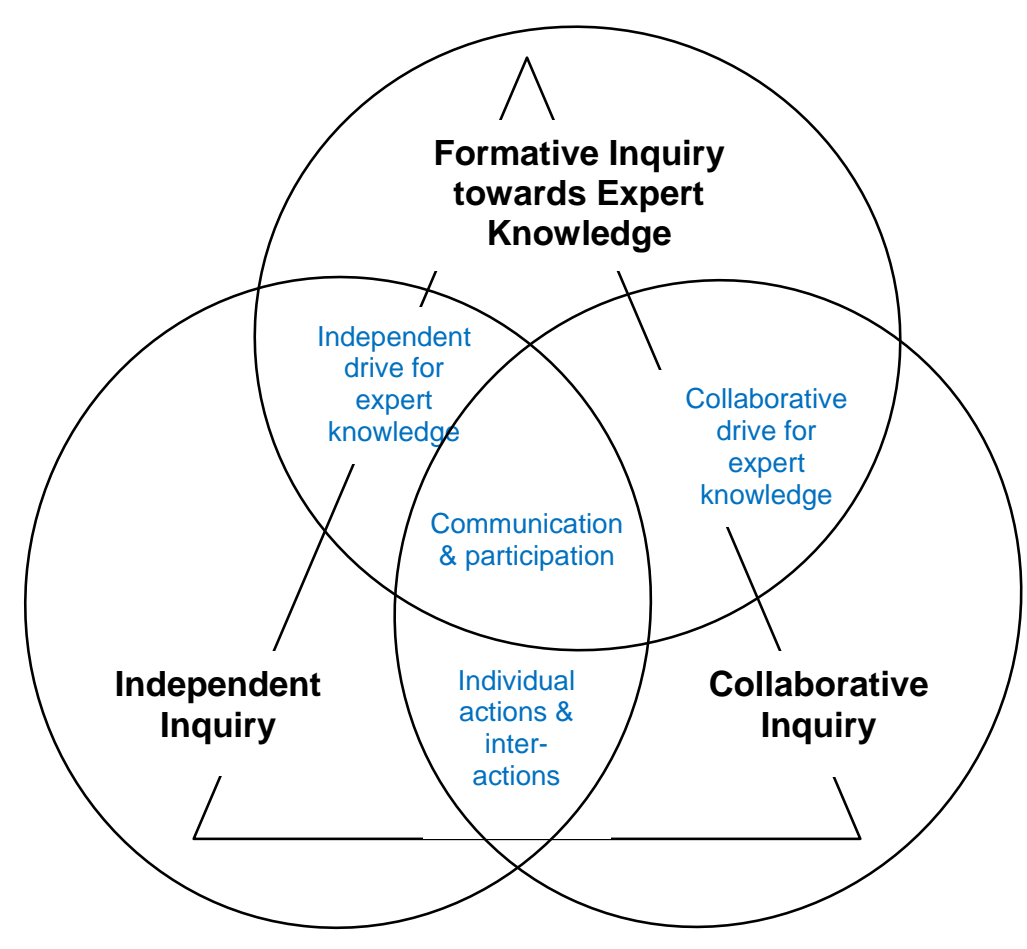

The three inquiries were derived from and categorized based on the observed learners' online communication behaviors. Using online tools and virtual networking, active learners exhibited very distinctive e-habits for searching, broadcasting, linking, sharing, contributing, and co-constructing knowledge and expertise.

Independent inquiry is characterized by the learner's desire and action working through online communication channels and technologies which enable him or her to think out loud, reflect, explore, search, and express him or herself independently, expressively, and without being interrupted. Such online channels or spaces provide the learners a center of focus where time and space are extended for their own purposes until they each are satisfied with their own advancements. They allow each and every learner to pursue his or her interests and build his or her expertise independently, and to do so at his or her own pace. 
The following posting serves as an example of a learner "thinking out loud" in this context:

The email survey article pointed out that Internet email users tended to communicate with a larger number of geographically distant users, and to have more communications per week than nonusers. Increased communication with non-native speakers of one's language may contribute to the “Am I making sense?” problem, but the number of communications may contribute even more. If I am typing 50 emails per week when I used to write 25 regular letters per week, I have less time to devote to each one. Perhaps that means I spend less time putting a "soul" into each message; perhaps I don't have enough time to think about my wording when compared to the time I had when I was composing half as many communications. On the other hand, isn't email faster to create than a paper letter? I'm just thinking out loud here.

The participant described her experience of "thinking out loud" as dialoguing with herself first before dialoguing with others. The active dialoguing with herself bore the same or more weight than dialoguing with others because this action of "thinking out loud" helped the other participants to think along the line and contribute their experiences.

The following is another example of "independent inquiry," which is presented through a learners' reflection:

Perhaps when engaged in imagination one can CONSCIOUSLY engage in critical reflection simultaneously. I will use my example of my classroom teaching experience. Since I have struggled with the discomfort of classroom teaching (fear of speaking in groups and actually making sense) I have consciously imagined different scenarios of teaching methods I would use while simultaneously reflecting on possible results (and assessments) of each method imagined. I suppose this is also a form of metacognition. It has helped me in the past, as the musician in me can relate this to a "rehearsal" of sorts ... only instead of the director giving me notes afterwards, I am critiquing myself.

In the above example, the participant initiated the idea that one could consciously engage in imagination and critical reflection at the same time. Then she used her classroom teaching experience to illustrate what she meant by such conscious thinking.

To a degree, a learner's independent inquiry process provides the first step towards collaboration. There is great evidence that the learner must have time, in a period of uninterrupped control, to form complete thoughts before he or she can go beyond his or her locus and is ready to collaborate. Additionally, as noted by Swan [22] and shown in this study, online course participants tend to communicate more in order to keep the communication equilibrium and to make up for the lack of co-presence.

Collaborative inquiry is highlighted by the active interplay between the participants, the influx and outflow of thoughts and ideas where the participants were seeking each other's respect, understanding, knowledge, critical thinking, and concurrence. This inquiry is characterized by the learner's desire for high interactivity and exchange, where he or she can reach out to peers, collaborate, share, question, challenge, contribute, and co-create inquiries and knowledge with others. Such activity allows learners to pursue topics of interest and inquiries collaboratively with others who have similar interests and to share and co-create knowledge. Collaborative inquiry helps learners not only teach themselves, but also teach, challenge, and co-create knowledge with their peers. The following examples show how online participants challenge each other with questions, how they build on each other's ideas, and how they cocreate ideas: 
Challenging each other:

Again I would ask you how exactly Sesame Street teaches children that learning is fun, if children don't even know that they are learning when watching Sesame Street? I think this point needs to be explained in more detail (at least for me to understand it).

Building on each other's ideas:

Media...Does It Think For Us? That's an interesting question. I think someone in an earlier post asked whether we influence media or media influences us. I really don't know the answer to that, but it does seem to go both ways. I would add on to your question of what is media's effect on society today and also ask what is influencing what, because I think the two questions are closely tied together. Honestly, I think it's hard to imagine that anyone would come right out and say that media is an extremely positive influence on society these days. But it's also really hard to imagine a life without it. I actually enjoy this fast-paces world we live in sometimes (and other times passionately hate it) and like parts of the new world that have been created by media. So it's a tough question to answer. I'd love to hear other thoughts.

\section{Co-creating ideas:}

I like this point about technology reflecting the user, AND the user's CHOICE of technology playing a role in how they define themselves. Has anyone had the experience of trying a new way of "organizing” all your data (music, journals, etc), and feeling totally unsettled? If, as Rudd posited, "there is no distinction between ourselves and our technologies," that would explain this phenomenon.

Formative inquiry towards expert knowledge combines aspects of both independent and collaborative inquiries described above. It is shaped and results from the individual learner's desire to test and vet results of independent inquiries through interactions with peers and experts. Formative inquiries help the learners to build, and help one another to build expert knowledge in online environments. They are evidenced in many different forms such as offering help, providing suggestions, solutions, pointers, and interpretations, differentiating patterns, and facilitating the online communication and learning environments. When different forms of expertise (or emergent expertise) are shared online, a new form of expert knowledge or an "aha” moment may emerge or be articulated by an individual. Sometimes several participants together build on one another's insight and understanding, which are revealed in the following examples:

Providing suggestions, solutions, and interpretations:

If you have a copy of the NYer Magazine, take a look at the lead articles for the past few weeks. They have given me some insight into the real issues involved in this conflict. The one about the European view of America going back to the 1850's was most insightful.

Building on ideas and Facilitation:

I think you are on the right track with the essence of the musical experience when you talk about being transformed by reading a novel. When I go to a chamber music concert in a very acoustically live hall or cathedral I can feel transformed, or is it transported to another realm. I think this has to do with the chemistry of the performers and the music itself. John probably could put this into a clear statement for us. Are you out there John?

Expertise is oftentimes knowledge in a relational sense. Expertise occurs as function of two or more 
people's relative knowledge, where one has greater knowledge or a particular subject. For instance, Jane may know about corporate training less than her colleague John, but she knows more about teacher training than he does. In one sense, we only become "experts" in relationship to the other people's knowledge bases. When different expertise was shared online, a new form of expert knowledge emerged. With different backgrounds, interests, and experiences, the participants were able to bring various depths and breadths of knowledge, make connections, and consequently, shape the "content to be learned." The learners started at different levels and left with different sets of understanding and skills, after they had all had impact on and raised the levels of consciousness and capacities of the learning environment, their own learning, and their colleagues' learning.

Further, there is a distinction between the "expertise" in singular form and the "expertise" in plural form. In a face-to-face learning environment, it is often the case that when the class participants are confined to a 45-minute or a one-and-half-hour class schedule, the general student expertise has little time to emerge. Expertise in its plural form can emerge more easily in an online learning environment. The participants can speak or write in an uninterrupted fashion asynchronously, synchronously, and without being constrained time or space. More importantly, a new type of dynamic expertise is arising from the online communication. Depending on a given topic, one participant may be good at keeping the flow of the conversation; one may know about certain technology aspects; one about pedagogical underpinnings, and one with more experiences, and one may have read more from a historical perspective. The multiple perspectives and contributions from these different individuals can be appreciated, instead of being seen as taking valuable time away from the focus or taking conversations off-track.

Together, the three inquiries play an important role in the learning process of each and every learner. To take best advantage of new technologies, we need to think very deeply about how these new technologies bring about new opportunities that did not exist even 5 to 10 years ago. With greater understanding and knowledge of the true nature of communication and learning, and of the conditions needed to help support learners' capacities for self-directed and collaborative learning, we will find that learners can accomplish more, achieve more potentials, and enjoy more rights to education.

\section{CONNECTING THE DOTS: THE ONLINE LEARNING MODEL, NEW MEDIA AND TECHNOLOGIES, AND RIGHTS TO EDUCATION}

The online learning model of three inquiries-independent inquiry, collaborative inquiry, and formative inquiry towards expert knowledge-emerged naturally from learners' online learning activities and interactivities. The model is supported by a wealth of evidence, which proves that distance learning, when equipped with new media and technologies, can provide extended opportunities for learners to achieve their full rights to education. These rights include the right to freedom of thought (Article 18), the right to freedom of peaceful assembly (Article 20), the right to participate in the cultural life of a community (Article 27), and the right to the full development of the human personality and to the strengthening of respect for human rights and fundamental freedoms (Article 26).

Why should anyone view any of these as basic human rights in the Internet age? One answer is that to deny a person these rights puts them at a greater disadvantage now than before, to the point where not only one's quality of life is in jeopardy, indeed, basic human freedoms will be denied. In the information age, since information and knowledge are the keys to human transformation, these become the tools by which humankind defines itself. In the not-too-distant future, to have or not to have, to receive or not to receive knowledge and information will be the equivalent of political and economic slavery. 
If we look at the history of communication, we will notice that our communication is becoming more independent of time and space. The expansion of communication from face-to-face conversation, to handwritten letters, and then to technology-mediated oral, visual, and written exchanges and dialogue represents a history of communication advances. Such advances enable us to communicate and learn at a much higher level of capacity, flexibility, and convenience. Methods and technologies of distance education including studies, lectures, activities, simulations, interactions and dialogues have evolved from paper, to print, to electronic media. Different methods and technologies shape the learning process and knowledge as well as affect the distribution of power among learners. As Pelto [58] indicated, "new technology brings new requirements in human skills and training, and usually results in social change as some types of persons are favored and others are handicapped by the new skills/knowledge requirements." With the introduction of print technology, the power structure of knowledge disbursement changed dramatically throughout Europe, as the clergy and the Roman Catholic Church had to give up their stranglehold on knowledge. The total body of human knowledge of the times was quickly distributed and disseminated to anyone who could read as texts were translated and created in vernacular languages $[59,60]$.

The Web and Internet have further revolutionized the power structure of knowledge creation and distribution. Today, few in the world can dispute the emergence of a type of global consciousness on issues such as global warming, world health, the global economy, terrorism, education or the positive impact of the Internet. Just as Vladimir Vernadsky's and Pierre Teilhard de Chardin's theory of the Noosphere [61] would suggest, the Internet itself can easily be seen as humankind's collective consciousness incarnate, shaping the biosphere, the atmosphere, and redefining the rights and possible rights of our children. And while we may no longer believe its progression to be unilinear as in the case suggested by orthogenesis, each of us can see that we are progressing toward some future state which will be made better or worse depending on our decisions about how we will embrace our rights to education on the planet. New media and technologies such as Web 2.0 and 3.0 will be placing greater and greater control, scalability, and speed to knowledge in the hands of the learner, and to deny the impact of these changes is to deny the proper planning for this eventual outcome. McClintock concluded that "digital technologies are now providing educators and students with tools of study, as opposed to tools of instruction" [62]. Learners are now taking advantage of digital technologies, developing their online communities, building collective knowledge bases such as blogs and wiki spaces, and advancing social awareness or their own political and or life agendas.

The Web 2.0 technologies are good examples that enable learners' control for their communications and learning. Web 2.0 is an umbrella term for many individual tools that have been created with web collaboration, sharing, and new information creation in mind. These technologies include weblogs, social bookmarking (e.g., delicious), wikis, podcasts, RSS (Really Simple Syndication) feeds and other forms of many-to-many publishing, social software, web application programming interfaces, and online web services such as eBay and Gmail, which provide a significant enhancement over read-only websites.

Weblogs or blogs, perhaps the most familiar example in the Web 2.0 realm, allow users to create a web presence (e.g., to post reflections, images, links without having to code or learn to use web authoring programs), receive comments, and connect to other like-minded people. The popularity of blog serves as another example that shows a learner's desire and action for independent inquiry as discussed in the previous section. The directness, contemporariness, intensity, and immediacy of a blog continue to be popular for learners to build a groundswell of solidarity.

New communication technologies have done an exceptional job reducing the cycle times required not only in basic processing times, but also in communication cycle times. These send-respond-reply cycles 
are now so compressed that they nearly approximate synchronous thoughts and interactions, or said another way, the lapse of "dead time" within the continuing dialogic flow puts the shared meaning more easily within everyone's grasp, and the dialogue can be kept alive and expanded. The asynchronicity of communication has become a conscious choice rather than a manageable affordance. As a result, more online dialogues are now taking place, more people have greater access to the ever-expanding knowledge base, and more people have the opportunities and capacities to contribute and create new knowledge. This is shown through the popularity of wiki technologies and the online communities that are supported by wiki technologies. Wiki technologies allow users to write collaboratively on a topic, publish it immediately, and update it frequently. Wikipedia, for instance, has not only become a web-based free content encyclopedia, but also a community with more than 75,000 active volunteer contributors working on some 9,000,000 articles in more than 250 languages (http://en.wikipedia.org/wiki/Wikipedia:About, retrieved on January 18, 2008). Both blog and wiki technologies have greatly increased the learners' opportunities and capabilities of pursuing independent inquiry, collaborative inquiry, and formative inquiry towards expert knowledge.

\section{DISCUSSIONS AND IMPLICATIONS}

The three types of inquiry discussed in the online model: independent inquiry, collaborative inquiry, and formative inquiry towards expertise mirror the homologous rights to freedom of thought, freedom to assemble and be part of a community, and the right to transformational education. Since these forms of inquiry are learner-centered, the learner operates with a high degree of control, flexibility, and potential. While there may continue to exist obstacles at the national, state, institutional, and policy level, it is enough to recognize that the first step in ensuring these rights for individual learners is to ensure that both learners and institutions are aware of the existence of the link between these dynamic inquiries so that they operate in conjunction with one another.

New media and technologies, in particular, web 2.0 technologies and social software create online environments where the learners start with a potential to be experts although they may not have the complete knowledge. They start as owners, creators or co-creators, having therefore more innate responsibilities. Such responsibilities call for learners to actively and enthusiastically participate in the learning and communication processes. Their efforts are also motivated by the ease of use, ease of creation, and ease of participation afforded by the new media and technologies. Equipped with new technologies and opportunities to communicate with other like-minded people, the learners will help one another rather than depend on the sole expert of an educator to find answers to their inquiries. Their rights to education evolve in the process addressing their learning through technology affordances of the future.

Although the model emerged from learners' online activities and interactivities, the model itself is applicable in various learning environments - online or offline, formal or informal. It is not bounded by time, space, or types of language. The advantage of having this generalized model is that educators and learners who are aware of its existence can now structure their communication and learning environments with the framework in mind so that the learners' experiences are fully developed and so the technologies are used to facilitate the learners' rights. What facilitates the success of real learning is not only access to quality information, but also access to like-minded people who are active participants and collaborators, and, more importantly, the opportunity for knowledge creation. Until educators and learners are aware that unless these three inquiries operation together, there is little synergy for the learner to achieve his or her full rights. 


\section{REFERENCES}

1. Universal Declaration of Human Rights. Article 26: http://www.un.org/Overview/rights.html:

a. Everyone has the right to education. Education shall be free, at least in the elementary and fundamental stages. Elementary education shall be compulsory. Technical and professional education shall be made generally available and higher education shall be equally accessible to all on the basis of merit.

b. Education shall be directed to the full development of the human personality and to the strengthening of respect for human rights and fundamental freedoms. It shall promote understanding, tolerance and friendship among all nations, racial or religious groups, and shall further the activities of the United Nations for the maintenance of peace.

c. Parents have a prior right to choose the kind of education that shall be given to their children.

2. Freire, P. Pedagogy of the Oppressed. New York: Seabury Press, 1970.

3. McClintock, R. Toward a place for study in a world of instruction. Teachers College Record 73(2): 161-206, 1971.

4. Candy, P. C. Self-directed Learning. San Francisco: Jossey-Bass, 1991.

5. Brookfield, S. Self-directed learning as a political idea. In G. A. Straka (Ed.), Conceptions of Selfdirected Learning: Theoretical and Conceptional Considerations. Berlin: Waxmann, 2000b.

6. Knowles, M. S. Self-directed Learning: A Guide for Learners and Teachers. Englewood Cliffs: Prentice Hall/Cambridge, 1975.

7. Merriam, S. B. The New Update on Adult Learning Theory. San Francisco: Jossey-Bass Publishers, 2001.

8. Merriam, S. B. \& R. S Caffarella. Learning in Adulthood: A Comprehensive Guide ( $2^{\text {nd }}$ ed.). San Francisco: Jossey-Bass, 1999.

9. Tough, A. The Adult's Learning Projects: A Fresh Approach to Theory and Practice in Adult Learning. Toronto: Ontario Institute for Studies in Education, 1979.

10. Brookfield, S. Lifelong Learning: Education Across the Lifespan. London and New York: Routledge/Falmer, 2000a.

11. Bates, A. W. Technology, E-learning and Distance Education (Studies in Distance Education) (2 ed.). Routledge, 2005.

12. Bourne, J., J. C. Moore, J. Sener, F. Mayadas \& L. F. Ettinger. Increasing Access in Online Higher Education. JALN, 10(3): 2006.

13. Garrison, D. R. Quality and access in distance education: theoretical considerations. In D. Keegan (Ed.), Theoretical Principles of Distance Education, 9-21. London, New York: Routledge, 1993.

14. Gilbert, S. W. If it ain't broke, improve it: Thoughts on engaging education for us all. Journal of Asynchronous Learning Networks 8(1): 2004.

15. Holmberg, B. Theory and practice of distance education. London; New York: Routledge, 1989.

16. Milliron, M. D., \& M. Prentice. Anytime, anyplace and the community college: Ten emerging insights. Journal of Asynchronous Learning Networks 8(1): 2004.

17. Moloney, J. F., \& B. Oakley, II. Scaling online education: Increasing access to higher education. Journal of Asynchronous Learning Networks 10(3): 2006.

18. Berge, Z. L., \& M. Collins (Eds.). Computer mediated communication and the online classroom. Cresskill, NJ: Hampton Press, 1995.

19. McConnell, D. Implementing computer supported cooperative Learning. Nichols Publishing Company, 1994.

20. Moore, M. G., \& W. G. Anderson. Handbook of distance education. Mahwah, N.J.: Lawrence Erlbaum Associates, 2003.

21. Sherry, L. Issues in Distance Learning. International Journal of Educational Telecommunications 1(4): 337-365, 1996. 
22. Swan, K. Learning effectiveness: What the research tells us. In J. Bourne \& J. C. Moore (Eds.), Elements of Quality Online Education, Practice and Direction, 13-45. Needham, MA: The Sloan Consortium, 2003.

23. Lin, L., P. Cranton \& B. Bridgall. Psychological type and asynchronous written dialogue in adult learning. Teachers College Record 107(8): 1788-1813, 2005.

24. Duffy, T. M. \& J. R. Kirkley. Learner-centered theory and practice in distance education: Cases from higher education. Mahwah, N.J.: Lawrence Erlbaum Associates, 2004.

25. Garrison, D. R. Self-directed learning and distance education. In M. G. Moore \& W. G. Anderson (Eds.), Handbook of Distance Education, 161-168. New Jersey, London: Lawrence Erlbaum Associates, 2003.

26. Harrison, N. How to Design Self-directed and Distance learning: A Guide for Creators of Web-based Training, Computer-based Training, and Self-study Materials. New York: McGraw-Hill, 1999.

27. Levine, S. J., \& LearnerAssociates.net. Making distance education work: Understanding learning and learners at a distance (1st ed.). Okemos, MI: LearnerAssociates.net, 2005.

28. Moore, M. Self-directed learning and distance education. Journal of Distance Education 1(1): 7-24, 1986.

29. Garrison, D. R., T. Anderson \& W. Archer. Critical thinking, cognitive presence and computer conferencing in distance education. American Journal of Distance Education 15(1): 7-23, 2001.

30. Garrison, D. R., T. Anderson \& W. Archer. A theory of critical inquiry on online distance education. In M. G. Moore \& W. G. Anderson (Eds.), Handbook of Distance Education, 113-127. New Jersey, London: Lawrence Erlbaum Associates, 2003.

31. McLoughlin, C. \& J. Luca. Cognitive engagement and higher order thinking through computer conferencing: We know why but do we know how? Teaching \& Learning Forum 2000. Curtin University of Technology, Australia, 2001.

32. Meyer, K. A. Face-to-face versus threaded discussions: The role of time and higher-order thinking. Journal of Asynchronous Learning Networks 7(3): 2003.

33. Rourke, L., T. Anderson, D. R. Garrison \& W. Archer. Assessing social asynchronous text-based computer conferencing. Journal of Distance Education, 14(2): 50-71, 1999.

34. Cunningham, S., S. Tapsall, Y. Ryan, L. Stedman, K. Bagdon \& T. Flew. New Media and Borderless Education: A Review of Convergence between Global Media Networks and Higher Education Provision. AGPS, Canberra, 1997.

35. Dede, C. J. The evolution of distance learning: Technology-mediated interactive learning. Journal of Research on Computers in Education 22: 247-264, 1990.

36. Daniel, J. S. Mega-Universities and Knowledge Media: Technology Strategies for Higher Education. London: Biddles Ltd., 1996.

37. Keegan, D. The Competitive Advantages of Distance Teaching Universities. Open Learning 9(2): 936, 1994.

38. Pea, R. A. Seeing what we build together: Distributed multimedia learning environments for transformative communications. Journal of the Learning Sciences 3(3): 285-299, 1994.

39. Brookfield, S. Understanding and Facilitating Adult Learning. San Francisco: Jossey-Bass, 1986.

40. Bohm, D. On Dialogue. London: Routledge, 1996.

41. Cole, M. Culture in Mind. Cambridge, MA: Harvard University Press, 1996.

42. Gadamer, H. Truth and Method. London: Sheed and Ward, 1979.

43. Buber, M. \& M. Friedman. The Knowledge of Man. New York: Harper \& Row, 1965.

44. Buber, M. I and Thou (2nd ed.). New York: Scribner, 1958.

45. Vygotsky, L. S. Mind in Society: The Development of Higher Psychological Processes. Cambridge, MA: Harvard University Press, 1978.

46. Koschmann, T. Computer Supported Collaborative Learning (CSCL): Theory and Practice of an Emerging Paradigm. Mahwah, NJ: Erlbaum, 1996. 
47. Salomon, G. No distribution without individual's cognition: A dynamic interactional view. In G. Salomon (Ed.), Distributed Cognitions: Psychological and Educational Considerations, 111-138. Cambridge, UK: Cambridge University Press, 1993.

48. Sorenson, E. K. \& E. S. Takle. Distributed collaborative learning across disciplines and national borders. In C. M. Hoadley \& J. Roschelle (Eds.), Proceedings of the Computer Support for Collaborative Learning (CSCL) 1999 Conference, 600-610. Palo Alto, CA. Stanford University, 1999.

49. Prietula, M. \& H. Simon. The experts in your midst. Harvard Business Review 67(1): 1989.

50. Bransford, J., J. Pellegrino \& M. Donovan. How people learn: Bridging research and practice. Washington, DC: National Research Council, National Academy Press, 1999.

51. Lave, J. \& E.Wenger. Situated Learning: Legitimate Peripheral Participation. Cambridge: Cambridge University Press, 1991.

52. van Manen, M. Researching Lived Experience: Human Science for an Action Sensitive Pedagogy. Albany: State University of New York Press, 1990.

53. Spiegleberg, H. The Phenomenological Moment: A Historical Introduction ( ${ }^{\text {rd }}$ ed.). The Hague: Martinus Nijhoff, 1982.

54. Cranton, P. No One Way: Teaching and Learning in Higher Education. Toronto: Wall \& Emerson, 1998.

55. Cranton, P. Becoming an authentic teacher in higher education. Melbourne, FL: Krieger, 2000.

56. Jung, C. Psychological Types. Princeton, NJ: Princeton University Press, 1971. (Original work published 1921.)

57. Lin, L. How Adults Learn through Online Asynchronous Written Dialogue. Unpublished dissertation, 2006.

58. Pelto, P. J. Snowmobiles: Technological revolution in the arctic. In H. R. Bernard \& P. J. Pelto (Eds.), Technology and Social Change (pp. 207-243). IL: Waveland Press, 1987.

59. Deibert, R. J. Parchment, Printing, and Hypermedia: Communication in World Order Transformation. New York: Columbia University Press, 1998.

60. Eisenstein, E. L. The Printing Revolution in Early Modern Europe. London: Cambridge University Press, 1983.

61. Teilhard de Chardin, P. Le Phénomène Humain. Seuil, Paris, 1955. (Translated as: The Phenomenon of Man. New York: Harper \& Row, 1959.)

62. McClintock, R. The education manifesto: Renewing the progressive bond with posterity through the social construction of digital learning communities, 1999. Retrieved January 20, 2008 from http://www.ilt.columbia.edu/publicAtions/manifesto/contents.html.

\section{ACKNOWLEDGEMENT}

I would like to thank Dr. Karen Swan, Dr. Albert Ingram, and Dr. Mark van 't Hooft for their comments and suggestions on earlier versions of this paper. My thanks also go to Dr. Robert Steiner and Dr. Janet Poley for their feedback.

\section{ABOUT THE AUTHOR}

Dr. Lin is currently assistant professor at the Department of Learning Technologies of University of North Texas. Lin's research interests include new media and technology, computer-mediated communication, cognition, online learning, professional development and adult learning. Lin holds an Ed. D. degree in Communication, Computing and Technology in Education from Teachers College, Columbia University. Visit http://courseweb.unt.edu/llin/ for more information. 